\title{
Postoperative pulmonary function changes according to the resected lobe: a 1-year follow-up study of lobectomized patients
}

\author{
Masanori Yokoba ${ }^{1,2}$, Tsuyoshi Ichikawa ${ }^{3}$, Shinya Harada ${ }^{2}$, Masahito Naito ${ }^{4}$, Yukitoshi Sato ${ }^{4}$, \\ Masato Katagiri ${ }^{1,2}$ \\ ${ }^{1}$ School of Allied Health Sciences, Kitasato University, Kanagawa, Japan; ${ }^{2}$ Department of Respiratory Medicine, Kitasato University Hospital, \\ Kanagawa, Japan; ${ }^{3}$ Rehabilitation Medicine Center, Tokai University Oiso Hospital, Kanagawa, Japan; ${ }^{4}$ Department of Pulmonary Surgery, Kitasato \\ University Hospital, Kanagawa, Japan \\ Contributions: (I) Conception and design: M Yokoba, T Ichikawa, M Katagiri; (II) Administrative support: M Yokoba; (III) Provision of study materials \\ or patients: M Yokoba, S Harada, M Naito, Y Sato, M Katagiri; (IV) Collection and assembly of data: M Yokoba, T Ichikawa, S Harada; (V) Data \\ analysis and interpretation: M Yokoba, T Ichikawa; (VI) Manuscript writing: All authors; (VII) Final approval of manuscript: All authors. \\ Correspondence to: Masanori Yokoba, MD, PhD. School of Allied Health Sciences, Kitasato University, Kitasato 1-15-1, Minami-ku, Sagamihara, \\ Kanagawa 252-0373, Japan. Email: myoko@kitasato-u.ac.jp.
}

Background: Pulmonary function and patient complaints appear to improve up to 12 months after lobectomy but long-term prospective studies based on clinical data are scarce. Improvement in pulmonary function may depend on the area and extent of the resection and the time from the operation. This prospective study aimed to determine pulmonary function changes according to the resected lobe.

Methods: This prospective study included 59 patients requiring single lobectomy. Total volume and lowattenuation volume (LAV) for each lobe and the entire lungs were calculated based on helical computed tomography images. Vital capacity (VC), forced expiratory volume in one second $\left(\mathrm{FEV}_{1}\right)$, percent $\mathrm{FEV}_{1}$ $\left(\% \mathrm{FEV}_{1}\right)$, percent lung diffusion capacity for carbon monoxide $\left(\% \mathrm{DL}_{\mathrm{co}}\right), \% \mathrm{DL}_{\mathrm{co}}$ divided by the alveolar volume $\left(\% \mathrm{DL}_{\mathrm{co}} / \mathrm{V}_{\mathrm{A}}\right)$, modified Medical Research Council (mMRC) grades, and COPD Assessment Test (CAT) scores were compared at 3, 6, and 12 months after surgery.

Results: VC was higher at 12 months than at 3 months after right upper lobectomy (RUL) or right lower lobectomy (RLL). $\mathrm{FEV}_{1}$ and $\% \mathrm{FEV}_{1}$ were higher at 12 months than at 6 months after left lower lobectomy (LLL). \% $\mathrm{DL}_{\mathrm{co}}$ was higher at 12 months than at 3 months after RUL or left upper lobectomy (LUL). DL ${ }_{\mathrm{co}}$ / $\mathrm{V}_{\mathrm{A}}, \mathrm{mMRC}$ grades, and CAT scores did not change significantly in the period from 3 to 12 months after any lobectomy procedure. Compared to the predicted postoperative values, the observed values of VC for RUL, RLL, and LUL; FEV 1 for RLL; $\% \mathrm{FEV}_{1}$ for RLL and LUL; \% $\mathrm{DL}_{\mathrm{co}}$ for LUL; and $\% \mathrm{DL}_{\mathrm{co}} / \mathrm{V}_{\mathrm{A}}$ for all lobectomy procedures were higher at 12 months.

Conclusions: Improvements in pulmonary function and symptoms varied according to the resected lobe. Some of the observed pulmonary function values were higher than the predicted postoperative values. Pulmonary function changes may be related to the location, volume, and extent of emphysematous changes.

Keywords: Lobectomy; low attenuation volume; postoperative pulmonary function

Submitted Aug 20, 2018. Accepted for publication Nov 16, 2018.

doi: $10.21037 /$ jtd.2018.11.108

View this article at: http://dx.doi.org/10.21037/jtd.2018.11.108

\section{Introduction}

Surgical resection is the best treatment for patients with lung cancer. However, postoperative evaluation of the pulmonary function is important for estimating the risk of complications and long-term disability after pulmonary resection. Predicted postoperative pulmonary function measures for forced expiratory volume in 1 second $\left(\mathrm{FEV}_{1}\right)$ 
and lung diffusion capacity for carbon monoxide $\left(\mathrm{DL}_{\mathrm{co}}\right)$ are considered the mainstays for patient selection before major lung resection. In a patient undergoing lobectomy, the "anatomical method" is used to calculate the predicted postoperative (ppo) $\mathrm{FEV}_{1}$ and $\mathrm{DL}_{\mathrm{co}}$. The guidelines from the European Respiratory Society and the European Society of Thoracic Surgery (ERS/ESTS) recommend the use of these ppo values to estimate the risk of death and cardiopulmonary complications after resection surgery (1).

Lung lobectomy destroys part of the lung parenchyma and its pulmonary function, but it sometimes results in an unexpected improvement of the remaining pulmonary function in some patients with moderate-to-severe emphysema (2). The emphysematous changes are often shown in the background of the resected lobe in patients with lung cancer. Lung lobectomy for cancer sometimes results in volume reduction in patients with emphysema (3). The degree of lung expansion, which occurs in order for the lung to occupy the thoracic cavity, also affects the remaining pulmonary function. In addition, air flow and blood flow are different in the upper and lower lobes. Therefore, pulmonary function may improve depending on the area and extent of the resection and the time elapsed from the operation.

Several studies have shown that the pulmonary function can change up to 6 months after lobectomy (4-6). However, the prospective study focused on the change of pulmonary function up to 12 months after lobectomy has not been reported. The aim of this prospective study was also to determine pulmonary function changes according to the resected lobe. The vital capacity (VC), $\mathrm{FEV}_{1}, \% \mathrm{FEV}_{1}$, $\% \mathrm{DL}_{\mathrm{co}}$, percent lung diffusion capacity for carbon monoxide divided by the alveolar volume $\left(\% \mathrm{DL}_{\mathrm{co}} / \mathrm{V}_{\mathrm{A}}\right)$, modified Medical Research Council (mMRC) dyspnea grade, and COPD Assessment Test (CAT) score were compared at 3, 6 and 12 months after single lobectomy by video-assisted thoracoscopic surgery (VATS).

\section{Methods}

\section{Patients}

Between December 11, 2013 and March 28, 2016, 59 patients scheduled to undergo single lobectomy by VATS at Kitasato University Hospital were prospectively enrolled in this study after providing their informed consent. This study was approved by the Kitasato University Medical
Ethics Organization (approval KMEO B13-110). Using the "Algorithm for Thoracotomy and Major Anatomical Resection" (7), high risk patients (ppoFEV ${ }_{1}$ or $\mathrm{ppo}_{\mathrm{D}} \mathrm{DL}_{\mathrm{co}}$ $<30 \%)$ were excluded as candidates for surgical treatment in our hospital. Patients underwent incentive spirometry before surgery according to the standard protocol for thoracic surgery in our hospital. However, they did not undergo focused perioperative or pulmonary rehabilitation before and after the surgery.

\section{Pulmonary function tests}

Pulmonary function tests were performed according to the guidelines of the Japanese Respiratory Society. Spirometric reference values of $\mathrm{VC}$, forced vital capacity (FVC), $\mathrm{FEV}_{1}$, and $\mathrm{FEV}_{1} / \mathrm{FVC}$ for Japanese adults were calculated with the LMS (lambda, mu, sigma) method (8).

$\mathrm{VC}, \mathrm{FEV}_{1}, \% \mathrm{FEV}_{1}, \% \mathrm{DL}_{\mathrm{co}}, \% \mathrm{DL}_{\mathrm{co}} / \mathrm{V}_{\mathrm{A}}, \mathrm{mMRC}$ grade, and CAT score were evaluated before the operation and at 3, 6, and 12 months postoperatively. A preoperative pulmonary function test was performed within one month prior to the surgery. For patients with chronic obstructive pulmonary disease (COPD), the preoperative pulmonary function test was performed more than 2 weeks after receiving treatment with a bronchodilator [inhaled longacting muscarinic antagonist (LAMA) and/or long-acting beta-agonist (LABA)], which was maintained throughout the study. The percent predicted $\mathrm{FEV}_{1}, \mathrm{VC}, \mathrm{DL}_{\mathrm{co}}$, and $\mathrm{DL}_{\mathrm{co}} / \mathrm{V}_{\mathrm{A}}$ were expressed as the percentage of the predicted values for age, gender, and height. COPD and its severity were defined according to the Global Initiative for Chronic Obstructive Lung Disease (GOLD) criteria.

\section{Prediction of the postoperative pulmonary function}

For $\mathrm{VC}, \mathrm{FEV}_{1}, \% \mathrm{FEV}_{1}, \% \mathrm{DL}_{\mathrm{c}}$, and $\% \mathrm{DL}_{\mathrm{co}} / \mathrm{V}_{\mathrm{A}}$, predicted postoperative (ppo) values were calculated based on the number of functioning/unobstructed segments to be removed during surgery (7): ppo value $=$ preoperative value $x(1-y / z)$, with $[y]$ the number of functional or unobstructed lung segments to be removed and $[\mathrm{z}]$ the total number of functional segments.

\section{Computed tomography (CT) scanning}

Helical CT scans were obtained using 64-detector row CT scanners (Optima 660; GE Healthcare, Tokyo, Japan). With 
the patient in the supine position, we obtained $1.25-\mathrm{mm}$ high-resolution CT images of the entire lungs during a deep inspiratory breath hold. We used a $512 \times 512$ matrix, a $1.25-\mathrm{mm}$ collimation, and a scan time of $0.5 \mathrm{~s}$, at $120 \mathrm{kVp}$ and $270 \mathrm{~mA}$. This was a routine practice, and thus, patients were not exposed to any additional radiation for the purpose of measuring the radiological parameters in this study.

\section{Image interpretation and data analysis}

Three-dimensional volume rendering lung images were created using a commercially available, user-friendly imaging software program (Ziostation $2^{\circledR}$; Ziosoft, Inc., Tokyo, Japan). Threshold limits of -600 to $-1,024 \mathrm{HU}$ were applied to segment the entire lungs and to exclude soft tissues surrounding the lungs and the large vessels, atelectasis, fibrosis, and tumors within the lung. The volume of a lung that was segmented by a certain threshold limit can be readily obtained with the imaging software program. We called the volume of the entire lungs (-600 to $-1,024 \mathrm{HU}$ ), the total lung volume (TLV). The lungs were divided into two areas: low-attenuation areas, representing emphysematous lung tissue (<-950 HU); and normalattenuation areas (-600 to $-950 \mathrm{HU})$, representing normal lung fields. We calculated the entire volume and the lowattenuation volume (LAV) for each lobe and the entire lungs.

\section{Statistical analysis}

To evaluate the patients' characteristics, preoperative data were compared to between non-COPD, GOLD 1 COPD, and GOLD 2 COPD groups using the Kruskal-Wallis test. Mean values for $\mathrm{VC}, \mathrm{FEV}_{1}, \% \mathrm{FEV}_{1}, \% \mathrm{DL}_{\mathrm{co}}$, and $\% \mathrm{DL}_{\mathrm{co}} / \mathrm{V}_{\mathrm{A}}$ were compared between (I) preoperative data and data obtained at 3, 6, and 12 months after lobectomy using the Friedman rank sum test; and (II) data obtained at 12 months and the ppo values using the Wilcoxon signed-rank test. mMRC grades and CAT scores were compared between pre-operation and 3, 6, and 12 months after lobectomy using the Friedman rank sum test. Holm corrections were used for post-hoc comparisons. A P value of less than 0.05 was considered statistically significant. All statistical analyses were performed with EZR (Saitama Medical Center, Jichi Medical University), which is a graphical user interface for R (The R Foundation for Statistical Computing, version 3.0.2) (9). More precisely, it is a modified version of $\mathrm{R}$ commander (version 2.0-3) that includes statistical functions that are frequently used in biostatistics.

\section{Results}

\section{Preoperative data}

Of the 75 patients eligible for VAT lobectomy, 16 were excluded because of chylothorax $(n=1)$, pyothorax $(n=2)$, lung cancer recurrence $(n=3)$, cerebral vascular infarction $(n=1)$, renal cell carcinoma $(n=2)$, and withdrawal of consent $(n=7)$. In addition, one of two pyothorax patient and a patient of cerebral vascular infarction were died within 12 months after surgery. Finally, 59 patients (mean age $69.0 \pm 8.2$ years; range $43-84$ years) with complete pulmonary function assessment were included in this study. The indications for lobectomy were adenocarcinoma $(n=44)$, squamous cell carcinoma $(\mathrm{n}=10)$, adenosquamous carcinoma $(\mathrm{n}=1)$, small-cell carcinoma $(\mathrm{n}=1)$, large cell neuroendocrine carcinoma $(n=1)$, pleomorphic carcinoma $(n=1)$, and benign lymphoproliferable disorder $(\mathrm{n}=1)$. Preoperative patient characteristics are described in Table 1. Current and former smokers discontinued their smoking habits before surgery. The majority of the patients, including 16 of 20 nonCOPD patients, 10 of 12 GOLD 1, and 7 of 8 GOLD 2 COPD patients, discontinued smoking more than 4 weeks prior to the pre-operational pulmonary function tests. The remaining 7 of 40 patients discontinued smoking just after the first set of pulmonary function tests. All patients discontinued smoking 24 hours prior to $\mathrm{DL}_{\mathrm{co}}$ (and $\mathrm{DL}_{\mathrm{co}} / \mathrm{V}_{\mathrm{A}}$ ) measurements of the first set of pulmonary function tests to prevent smoking from affecting the results of the test. Thereafter, none of them resumed smoking.

The mean \% LAV of the resected lobe [(LAV of the resected lobe/volume of the resected lobe) $\times 100$ ] for the GOLD 2 group was higher than that for the non-COPD group. The mean \% LAV of the entire lungs [(LAV of the entire lungs/volume of the entire lungs) $\times 100$ ] for the GOLD 2 groups was also higher than that for the nonCOPD group, yet not significantly so $(\mathrm{P}=0.055)$. There was no difference between groups for the LAV ratio between the resected lobe and the entire lungs (LAV of the resected lung/ LAV of the entire lungs). The number of lobectomies and their mean LAV of the resected lobe are shown in Table 2. The mean \%LAV of each lobe varied between $0.57 \%$ and $73.52 \%$. The upper lobes, especially the left upper lobe (LUL), had higher \%LAV values than the lower lobes. 
Table 1 Preoperative patient characteristics

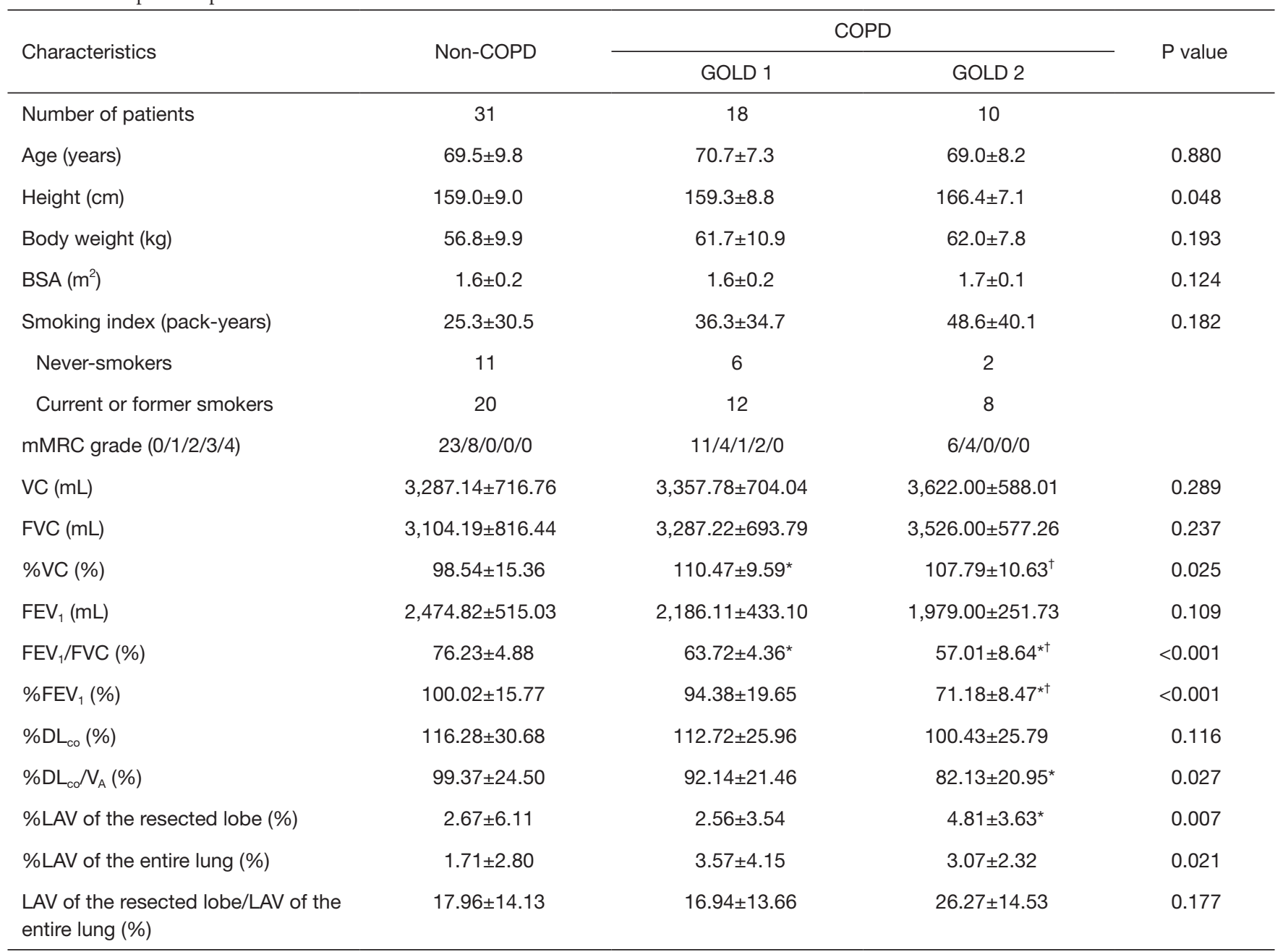

Values are represented mean $\pm \mathrm{SD} .{ }^{*}$, significantly different from the non-COPD group; ${ }^{\dagger}$, significantly different from the GOLD 1 group. $\mathrm{P}<0.05$ was set as statistically significant. $\mathrm{BSA}$, body surface area; COPD, chronic obstructive pulmonary disease; $\mathrm{DL}_{c 0}$, lung diffusion capacity for carbon monoxide; $\mathrm{DL}_{c o} / \mathrm{V}_{\mathrm{A}}$, lung diffusion capacity for carbon monoxide divided by the alveolar volume; $F E V_{1}$, forced expiratory volume in one second; FVC, forced vital capacity; GOLD, Global Initiative for Chronic Obstructive Lung Disease; LAV, lowattenuation volume; mMRC, modified Medical Research Council; VC, vital capacity.

\section{Video-assisted thoracoscopic surgery for lobectomy and postoperative pain}

PURE VATS using a 3-port technique was performed in 13 patients (9 non-COPD, 3 GOLD 1, and 1 GOLD 2 COPD) by four thoracic surgeons, and ASSIST VATS was performed in 46 patients by seven thoracic surgeons in our division. PURE VATS was used for 7 RUL lobectomies, 5 RLL lobectomies, and 1 LLL lobectomy. None of the patients underwent conversion from VATS to open thoracotomy. Epidural analgesia was used during the surgeries. All patients received patient-controlled epidural analgesia (PCEA) until postoperative day (POD) 2 or 3. Thereafter, NSAIDs and/or opioid pain medications, such as tramadol hydrochloride, were administered during the hospitalization period, on an "as required" basis until 8 weeks after surgery. The pulmonary function tests obtained at 3, 6, and 12 months after surgery were performed under pain-free conditions and no patients complained of postoperative pain during the pulmonary function tests. 
Table 2 Percentage of low-attenuation volume of the resected lobe compared to the entire lung

\begin{tabular}{|c|c|c|c|c|c|}
\hline Variable & Right upper lobe & Right middle lobe & Right lower lobe & Left upper lobe & Left lower lobe \\
\hline $\begin{array}{l}\text { LAV of the resected lobe/LAV of the entire } \\
\text { lung }(\%) \text {, mean } \pm S D \text { (range) }\end{array}$ & $\begin{array}{l}20.51 \pm 17.09 \\
(6.04-73.52)\end{array}$ & $\begin{array}{c}32.53 \pm 8.16 \\
(26.76-38.30)\end{array}$ & $\begin{array}{l}11.13 \pm 8.26 \\
(0.57-27.36)\end{array}$ & $\begin{array}{c}27.97 \pm 11.10 \\
(15.33-55.65)\end{array}$ & $\begin{array}{l}12.41 \pm 9.16 \\
(2.59-28.52)\end{array}$ \\
\hline
\end{tabular}

Values are represented as mean \pm SD. GOLD, Global Initiative for Chronic Obstructive Lung Disease; LAV, low-attenuation volume.

\section{Pulmonary function and symptoms after lobectomy}

Only one GOLD 1 COPD patient developed pneumonia on the sixth postoperative day. He was treated by antibiotics for 7 days and had an uneventful recovery. He required low flow oxygen therapy, but did not require high flow oxygen therapy or mechanical ventilation (invasive or noninvasive ventilation). Other patients did not suffer from postoperative complications such as pneumonia, and did not require invasive or non-invasive mechanical ventilation postoperatively. Three patients who had LUL involvement required domiciliary oxygen therapy at the time of hospital discharge which was withdrawn within 3 months after surgery. One of them was GOLD 1 and the others were GOLD 2 COPD patients who had quit smoking several years ago. Among these patients, \%LAV of the resected lobe measured $7.66 \%, 6.27 \%$, and $10.68 \%$ and the ratio of LAV of resected lobe/LAV of entire lung was $20.18 \%$, $15.33 \%$, and $24.03 \%$.

Table 3 and Figure 1 shows the preoperative values, postoperative values at 3,6 , and 12 months after lobectomy, and ppo values for $\mathrm{VC}, \mathrm{FEV}_{1}, \mathrm{FEV}_{1}, \mathrm{ODL}_{\mathrm{co}}$, and $\% L_{c o} / V_{\mathrm{A}}$. The patients with right middle lobectomy (RML) were excluded from this analysis because of the small number of subjects. Table 4 shows the preoperative and postoperative values at 3,6 , and 12 months after lobectomy for $\mathrm{mMRC}$ grade and CAT score.

\section{Preoperative and postoperative values}

Postoperative VC values from 3 to 12 months were lower than the preoperative values for each lobectomy location. $\mathrm{FEV}_{1}$ and $\% \mathrm{FEV}_{1}$ values from 3 to 12 months were also lower than the preoperative values, with the exception of the values at 6 months for the right lower lobectomy (RLL) and at 12 months for the left lower lobectomy (LLL). $\mathrm{DL}_{\text {со }}$ values from 3 to 12 months were lower than the preoperative values, while $\mathrm{DL}_{\mathrm{co}} / \mathrm{V}_{\mathrm{A}}$ values were not, with the exception of the values at 3 months for the right upper lobectomy (RUL). Both mMRC grade and CAT score were higher after lobectomy. mMRC grades at 3 months for RUL and at 6 and 12 months for LUL were significantly higher than the preoperative values.

\section{Changes in postoperative values from 3 to 12 months after lobectomy}

$\mathrm{VC}$ values at 6 and 12 months were higher than at 3 months for RUL, and values at 12 months were higher than at 3 and 6 months for RLL. In contrast, there were no differences between 3, 6, and 12 months for left lung lobectomy (LUL and LLL). For FEV ${ }_{1}$, only LUL at 12 months was higher than at 6 months. $\% \mathrm{FEV}_{1}$ for LUL at 12 months was also higher than at 6 months. $\% \mathrm{FEV}_{1}$ at 6 months was higher than at 3 months, but it did not differ from that at 12 months for right lung lobectomy (RUL and RLL). $\% \mathrm{DL}_{\text {co }}$ at 6 and 12 months was higher than at 3 months for RUL, and that at 12 months was also higher than at 3 months for LUL. In addition, there were no differences between 3, 6, and 12 months for both RLL and LLL. In contrast, $\mathrm{DL}_{\mathrm{co}} / \mathrm{V}_{\mathrm{A}}$ showed no significant changes from 3 to 12 months for any of the lobectomies. Neither mMRC grade nor CAT score showed significant changes from 3 to 12 months for any of the lobectomies.

\section{Predicted postoperative values and values obtained at} 12 months after lobectomy

The obtained values at 12 months of (I) VC for RUL, RLL, and LUL; (II) FEV 1 for RLL; (III) $\% \mathrm{FEV}_{1}$ for RLL and LUL; (IV) $\% \mathrm{DL}_{\mathrm{co}}$ for LUL; and (V) $\% \mathrm{DL}_{\mathrm{co}} / \mathrm{V}_{\mathrm{A}}$ for all lobectomies were higher than the ppo values. Table 5 shows the numbers and percentages of patients who had lower pulmonary function values at 12 months after lobectomy than the calculated ppo values. With respect to the VC, $\mathrm{FEV}_{1}$ and $\% \mathrm{FEV}_{1}$ values, more non-COPD and GOLD 1 COPD patients showed smaller actual values at 12 months after surgery than the ppo values, than GOLD 2 COPD patients. With respect to the \%DLco, more GOLD 1 and GOLD 2 COPD patients showed smaller actual 12-month values compared to the ppo values, than non-COPD 
Table 3 Changes in pulmonary function at 3, 6, and 12 months after lobectomy

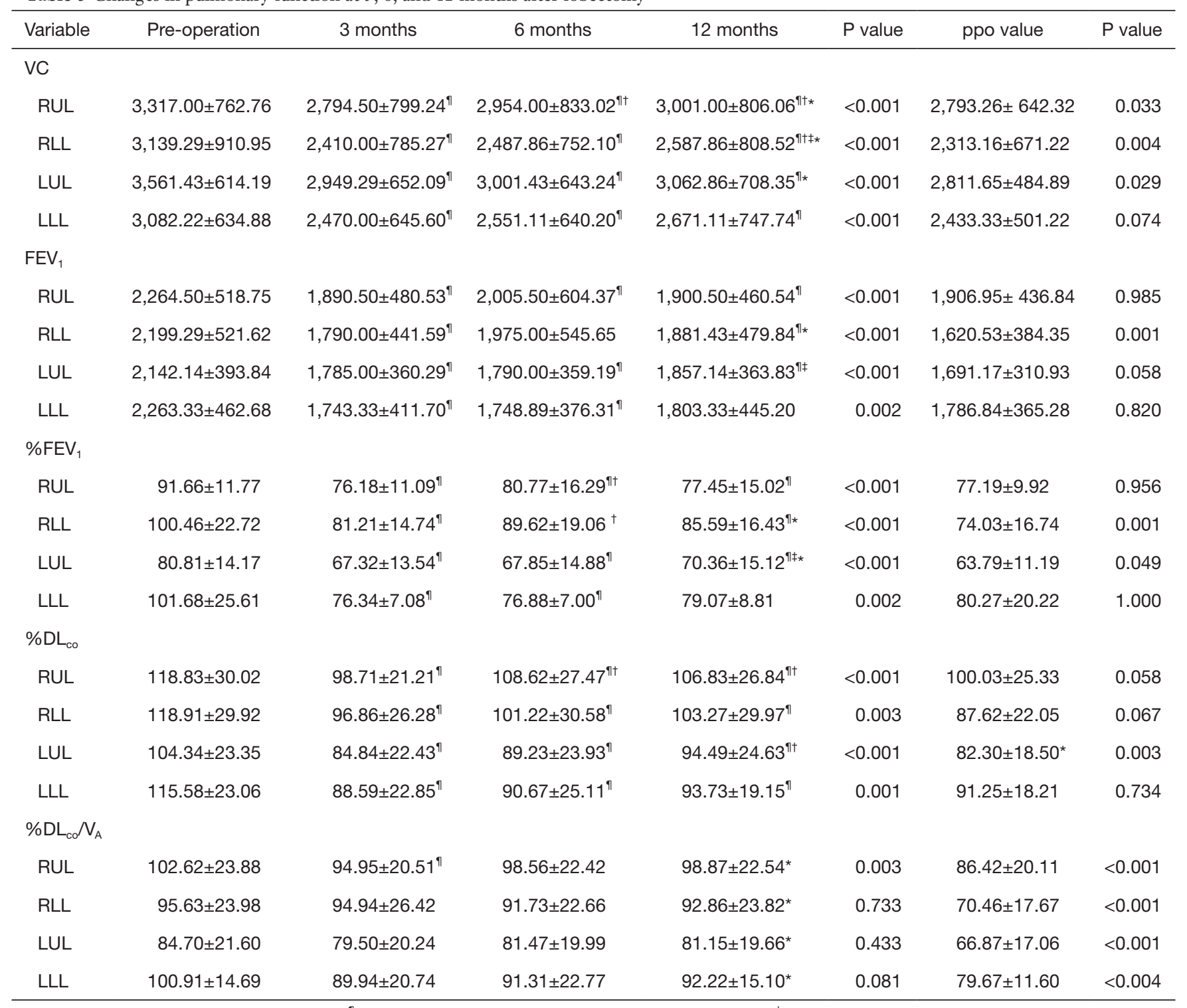

Values are represented as mean \pm SD. ", significantly different compared to pre-operation; ${ }^{\dagger}$, significantly different compared to 3 months; ${ }^{\ddagger}$, significantly different compared to 6 months values; *, significantly different compared to the ppo value. $\mathrm{P}<0.05$ was set as statistically significant. $\mathrm{DL}_{\mathrm{co}}$, lung diffusion capacity for carbon monoxide; $\mathrm{DL}_{\mathrm{co}} / \mathrm{V}_{\mathrm{A}}$, lung diffusion capacity for carbon monoxide divided by the alveolar volume; $\mathrm{FEV}_{1}$, forced expiratory volume in one second; LLL, left lower lobectomy; LUL, left upper lobectomy; ppo, predicted postoperative; RLL, right lower lobectomy; RUL, right upper lobectomy; VC, vital capacity.

patients. For $\% \mathrm{DL}_{\mathrm{co}} / \mathrm{V}_{\mathrm{A}}$, the actual number of patients who showed small actual value at 12 months after surgery compared to the ppo value were less than those for $\% \mathrm{DL}_{\mathrm{co}}$.

\section{Discussion}

Several studies have established a correlation between predicted and observed postoperative pulmonary function values (10-12). However, only few have considered the surgical methods and postoperative evaluation times $(5,6)$.

Many of our patients complained of postoperative pain at 1-2 months after surgery, but the pulmonary function could not be evaluated correctly at that time point. Therefore, we decided to perform the pulmonary function tests at 

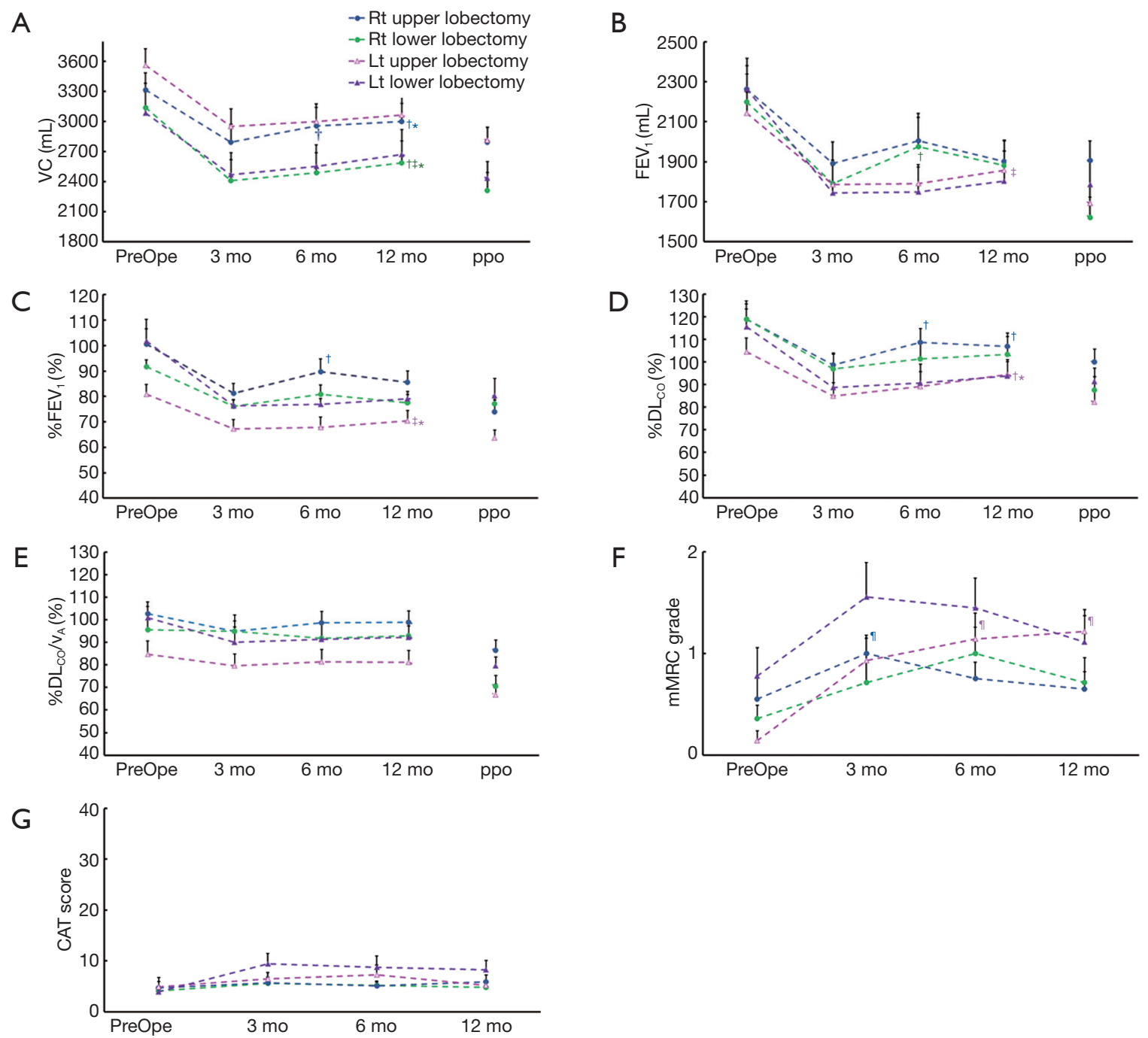

Figure 1 Changes in pulmonary function tests and symptoms according to follow-up duration and resected lobe: (A) vital capacity (VC); (B) forced expiratory volume in one second $\left(\mathrm{FEV}_{1}\right)$; (C) percent $\mathrm{FEV}_{1}\left(\% \mathrm{FEV}_{1}\right)$; (D) percent lung diffusion capacity for carbon monoxide $\left(\% \mathrm{DL}_{\mathrm{co}}\right) ;(\mathrm{E}) \% \mathrm{DL}_{\mathrm{co}}$ divided by the alveolar volume $\left(\% \mathrm{DL}_{\mathrm{co}} / \mathrm{V}_{\mathrm{A}}\right)$; (F) modified Medical Research Council (mMRC) grades; (G) COPD Assessment Test (CAT) scores. Values are mean $\pm \mathrm{SEM},{ }^{\dagger}, \mathrm{P}<0.05$ compared to 3 months; ${ }^{\ddagger}, \mathrm{P}<0.05$ compared to 6 months; ${ }^{*}, \mathrm{P}<0.05$ compared to ppo; "I, $\mathrm{P}<0.05$ compared to the pre-operation.

3 months postoperatively for short-term follow-up. In some of the patients, the symptoms and pulmonary function kept improving until 12 months postoperatively. So far, few studies have reported changes in pulmonary function at 12 months after surgery (13). Thus, we decided to perform the pulmonary function tests at 6 and 12 months for middleand long-term follow-up. The International Association for the Study of Pain (14) defines chronic postsurgical pain as pain persisting at least 3 months after surgery. It was reported that after VATS lobectomies, $7.5-25 \%$ of patients will have chronic pain $(15,16)$. In contrast, our patients did not complain of postoperative pain and did not require pain relief medications beyond 3 months after thoracic surgery. We believe the pulmonary function tests obtained at 3, 6 ad 12 months after surgery were performed under pain-free conditions.

The postoperative lung volume and its function may change depending on the resected lobe (17). In patients with emphysema, lung lobectomy may result in volume reduction $(3,12)$. Then, LAV values were calculated with 
Table 4 Changes in mMRC grades and CAT scores at 3, 6, and 12 months after lobectomy

\begin{tabular}{|c|c|c|c|c|c|}
\hline Variable & Pre-operation & 3 months & 6 months & 12 months & $P$ value \\
\hline RUL & $0.55 \pm 0.94$ & $1.00 \pm 0.79^{\pi}$ & $0.75 \pm 0.72$ & $0.65 \pm 0.75$ & 0.025 \\
\hline RLL & $0.36 \pm 0.50$ & $0.71 \pm 0.73$ & $1.00 \pm 0.96$ & $0.71 \pm 0.91$ & 0.135 \\
\hline LUL & $0.14 \pm 0.36$ & $0.93 \pm 0.82$ & $1.14 \pm 0.95^{\Uparrow}$ & $1.21 \pm 0.80^{\pi}$ & $<0.001$ \\
\hline \multicolumn{6}{|c|}{ CAT score } \\
\hline RUL & $3.25 \pm 3.02$ & $5.60 \pm 3.93$ & $5.15 \pm 3.99$ & $4.80 \pm 4.27$ & 0.884 \\
\hline RLL & $4.71 \pm 4.56$ & $5.64 \pm 4.50$ & $5.14 \pm 2.71$ & $5.93 \pm 4.94$ & 0.884 \\
\hline LUL & $4.86 \pm 6.93$ & $6.50 \pm 4.69$ & $7.29 \pm 6.92$ & $5.21 \pm 3.45$ & 0.124 \\
\hline
\end{tabular}

Values are represented as mean $\pm \mathrm{SD}$. ", significantly different compared to pre-operation. $\mathrm{P}<0.05$ was set as statistically significant. CAT, COPD assessment test; LLL, left lower lobectomy; LUL, left upper lobectomy; mMRC, modified Medical Research Council; RLL, right lower lobectomy; RUL, right upper lobectomy.

Table 5 Numbers and percentage of patients having smaller pulmonary function values at 12 months after lobectomy than the calculated ppo values

\begin{tabular}{lccc}
\hline Variable & Non-COPD (\%) (N=31) & GOLD 1 COPD (\%) (N=18) & GOLD 2 COPD (\%) (N=10) \\
\hline VC & $10(32.3)$ & $4(22.2)$ & $2(20.0)$ \\
$\mathrm{FEV}_{1}$ & $10(32.3)$ & $7(38.9)$ & $2(20.0)$ \\
$\% \mathrm{FEV}_{1}$ & $10(32.3)$ & $7(38.9)$ & $2(20.0)$ \\
$\% \mathrm{DL}_{\mathrm{cO}}$ & $8(25.8)$ & $7(38.9)$ & $3(30.0)$ \\
$\% \mathrm{DL}_{\mathrm{co}} \mathrm{N}_{\mathrm{A}}$ & $3(9.68)$ & $1(5.56)$ & $1(10.0)$ \\
\hline
\end{tabular}

Values are represented as number and percentage.

three-dimensional CT to evaluate the emphysematous changes, which were considered to influence a patient's recovery.

Postoperative complications such as pneumonia, and/or the postoperative requirement for mechanical ventilation sometimes play a role in lung function impairment following surgery. In this study, one patient had pneumonia, but recovered uneventfully. In his case, we believe that the pulmonary function tests obtained after surgery were not affected by such issues.

Several investigators had reported that postoperative incentive spirometry did not improve overall recovery of lung function or frequency of postoperative pulmonary complications $(18,19)$. In this study, our patients did not agree to undergo postoperative rehabilitation as they wanted to return to work and get back into society earlier; therefore, we could not estimate the relationship between postoperative complications and postoperative rehabilitation, including physiotherapy and incentive spirometry.

\section{Improvement of the pulmonary function according to the resected lobe}

$\mathrm{VC}$ is a lung volume measurement that can be measured as slow VC or FVC. There is little or no difference between $\mathrm{VC}$ and FVC in normal subjects (20). However, FVC sometimes becomes smaller than $\mathrm{VC}$ in patients with COPD because of airflow limitations (20-22). Thus, slow VC, and not FVC, was assessed to avoid an underestimate of the pulmonary function in both non-COPD and COPD patients in this study.

To estimate the risk of complications, including atelectasis and pneumonia, thoracic surgery-related 
mortality (23-25), VC or FVC, and $\mathrm{FEV}_{1}$ have been studied in the last quarter of the 1900s $(10,25,26)$ Current guidelines from the American College of Chest Physicians (ACCP) and the ERS recommend the use of not only $\mathrm{FEV}_{1}$, but also $\mathrm{DL}_{\text {co }}$ and maximal oxygen consumption $\left(\mathrm{VO}_{2}\right)$ to assess the risk of complications associated with lung resection $(1,7)$. In clinical practice, stair climbing or the shuttle walk test is used because $\mathrm{VO}_{2}$ testing is not practical.

Sengul et al. (17) reported that FVC decreased more 3 months after lower lobectomy than after upper lobectomy in 30 patients who underwent lung resection. In their study, CT images taken in supine position showed higher postoperative contralateral lung expansion and minor volume loss of the remaining ipsilateral lung in lower lobectomy, especially right lower lobectomy.

In our study, we did not analyze the volume changes for each remaining lobe by CT images. However, we found that VC observed in the supine position kept increasing until 12 months after right upper or lower lobectomy more than after left lobectomy. Anatomically, the heart might prohibit the expansion of the remaining left lobe after leftside lobectomy compared to the expansion of the right lobe after right-side lobectomy. Another explanation is that after right-side lobectomy, there remain two ipsilateral lobes, whereas after left-side lobectomy, only one ipsilateral lobe remains.

One previous investigation reported that $\mathrm{FEV}_{1}$ did not improve further after 3 months until 6 months after lobectomy (6). In our study, patients with LUL showed increased $\mathrm{FEV}_{1}$ and $\% \mathrm{FEV}_{1}$ at 12 months compared to 3 months without significantly increasing VC. This discrepancy may be related with the methods of analysis, which focused on the resected lobe or not. The improvements of $\mathrm{FEV}_{1}$ and $\% \mathrm{FEV}_{1}$ in patients with $\mathrm{LUL}$ may be explained by the fact that LUL will lose more emphysematous lung parenchyma than other lobectomized patients.

When pulmonary emphysema progresses, the alveolus gas exchange area decreases because the alveolus wall is destroyed, and blood flow decreases because the pulmonary capillary bed is destroyed, thus reducing $\mathrm{DL}_{\mathrm{co}}$. If the $\mathrm{V}_{\mathrm{A}}$ reflects the gas exchange area, $\mathrm{DL}_{\mathrm{co}} / \mathrm{V}_{\mathrm{A}}$ indicates $\mathrm{DL}_{\mathrm{co}}$ per unit of gas exchange area. In the actual measurements, total lung capacity (TLC) is used instead of the $\mathrm{V}_{\mathrm{A}}$. Patients with COPD who have larger TLC have a $\% \mathrm{DL}_{\mathrm{co}} / \mathrm{V}_{\mathrm{A}}$ that is smaller than $\% \mathrm{DL}_{\mathrm{co}}$. In our study, TLC was measured at each time point and $\mathrm{DL}_{\mathrm{co}} / \mathrm{V}_{\mathrm{A}}$ was calculated.

Lobectomy affects the lung parenchyma including the alveolar and pulmonary capillary bed, but the total amount of blood remains unchanged. The remaining lung tissue is subjected to an increased pulmonary artery flow (27). That results in pulmonary capillary recruitment and distension for the remaining capillary bed and keeps $\% \mathrm{DL}_{\mathrm{co}} / \mathrm{V}_{\mathrm{A}}$ after surgery comparable to the preoperative values. RLL consisting of 5 segments leads to a reduction in the gas exchange area by $66 \%$ more than RUL composed of 3 segments $\{[(5 / 3)-1] \times 100=66 \%\}$, while LUL and LLL lead an equal loss of gas exchange area (50\% each). Both ventilation and blood flow per unit volume decrease from the bottom to the top of the upright lung. In addition, the percentage of LAV was larger in the upper lobes than in the lower lobes in our subjects. Lower lobe lobectomy loses $50 \%$ of one lung with larger ventilation and blood flow, leaving one lower lobe with smaller LAV and two upper lobes with larger LAV. The pulmonary capillary recruitment and distension on those remaining "worse" lobes can keep the overall $\% \mathrm{DL}_{\mathrm{co}}$, but do not improve from 3 to 12 months after surgery. On th e other hand, upper lobe lobectomy loses $30-50 \%$ of one lung with smaller ventilation and blood flow, leaving two lower lobes with smaller LAV and one upper lobe with larger LAV. The pulmonary capillary recruitment and distension on those remaining "better" lobes showed improved $\% \mathrm{DL}_{\mathrm{co}}$ after surgery.

Assessing $\% \mathrm{DL}_{\mathrm{co}} / \mathrm{V}_{\mathrm{A}}$ is as important as $\% \mathrm{DL}_{\text {co }}$ for understanding the patients' status pathophysiologically. However, only few studies have focused on the changes of $\mathrm{DL}_{\mathrm{co}} / \mathrm{V}_{\mathrm{A}}$ for pre- and post-lung resection. Our current study supports the previous investigation that the $\mathrm{DL}_{\text {co }}$ falls after pulmonary resection, but $\mathrm{DL}_{\mathrm{co}} / \mathrm{V}_{\mathrm{A}}$ does not decrease (28). In addition, indication for lung resection may be considered with stable $\% \mathrm{DL}_{\mathrm{co}} / \mathrm{V}_{\mathrm{A}}$, which did not change from preoperation to 12 months after surgery compared to $\% \mathrm{DL}_{\mathrm{co}}$.

\section{Preoperative predicted lung function and postoperative values at 12 months after lobectomy}

The evaluation of postoperative pulmonary function is important for patient selection before lung surgery. Postoperative pain can cause a number of peri- and postoperative complications both immediately and long after the surgery (29). Most pulmonary function tests require the patient's effort and that effort sometimes causes pain, possibly resulting in pulmonary function underestimation. Therefore, we compared the ppo values and the actual values obtained at 12 months after surgery.

$\mathrm{VC}, \mathrm{FEV}_{1}$, and $\mathrm{DL}_{\text {co }}$ decreased over time. However, 
$\mathrm{VC}$ at 12 months was higher than the ppo value, except for LLL. $\% \mathrm{FEV}_{1}$ and $\% \mathrm{DL}_{\mathrm{co}}$ are usually used for patient's selection before major lung resection (1). However, $\mathrm{FEV}_{1}, \% \mathrm{FEV}_{1}$, and $\% \mathrm{DL}_{\text {со }}$ at 12 months after lobectomy were sometimes higher than the ppo values. That is not related with lobular volume or LAV of the resected lobe. Interestingly, the actual values and ppo values of not only $\% \mathrm{FEV}_{1}$ and $\% \mathrm{DL}_{\mathrm{co}}$, but also $\mathrm{FEV}_{1}$ and $\mathrm{VC}$ were similar for LLL. Patient selection based on the ppo might be stricter for lower lobectomy planned patients than for other lobectomy patients. When the focus is shifted from the resected lobe to the presence or severity of COPD, nonCOPD and GOLD 1 COPD patients appear to have a tendency of lower recovery with respect to $\mathrm{VC}, \mathrm{FEV}_{1}$ and $\% \mathrm{FEV}_{1}$ values than GOLD 2 patients. The number of patients who showed a small recovery of $\mathrm{DL}_{\mathrm{co}}$ was larger than that for $\% \mathrm{DL}_{\mathrm{co}} / \mathrm{V}_{\mathrm{A}}$, regardless of the presence or absence of COPD.

\section{Changes in symptoms between pre-operation and post- operation}

The mMRC grade and CAT score became higher than the preoperative values, but only LUL and RUL showed significant changes after lobectomy, because of their wide variations. The patients who underwent upper lobe lobectomy had higher mMRC grade after surgery, while the LLL group tended to have higher CAT score compared to the other groups. mMRC and CAT questionnaires focus on different aspects: $\mathrm{mMRC}$ focuses on the degree of breathlessness related to activity (30) and CAT assesses all aspects of the impact of COPD (cough, sputum, breathlessness, chest tightness, confidence, activity, sleep, and energy levels) on a 1 - to 5 -point scale that measures health-related quality of life (31). In this study, the number of non-COPD, GOLD 1 COPD, and GOLD 2 COPD patients who had a CAT score $\geq 10$ was $1 / 4 / 1$ preoperatively and $4 / 3 / 1$ at 12 months after lobectomy. By contrast, the number of patients with an mMRC grade $\geq 2$ was $1 / 3 / 0$ preoperatively and $1 / 3 / 0$ at 12 months after lobectomy. The changes in those scores were not related with the changes in pulmonary function, percent volume of the resected lobe, or the emphysematous LAV of the resected lobe. Patients with lung cancer diagnosed as GOLD 3 or 4 or having higher LAV on the resected lobe might show volume reduction effects after lobectomy $(2,12)$. However, the National Emphysema Treatment Trial suggested that patients with a homogeneous emphysema distribution and very low $\mathrm{FEV}_{1}$ (predicted $<20 \%$ ) are high-risk patients for surgical lung volume reduction (32).

The GOLD 1 and GOLD 2 patients who required temporary domiciliary oxygen therapy had higher level of \%LAV of resected left upper lobe than the other LUL patients, and the ratio of the LAV of resected lobe/LAV of the entire lung was low. In case of LUL involvement, if the left upper lobe had a higher \%LAV than the LUL itself, and a lower LAV ratio compared to the LAV of entire lung, domiciliary oxygen therapy might be needed for a while.

\section{Study limitations}

First, the number of patients per lobectomy location was small. The total number of lobectomies by VATS lobectomy has been increasing, but it is not easy to match the number of resected lobes and the number of patients who are diagnosed as non-COPD or COPD with GOLD classification. Second, there were no high-risk patients in this study. We found the $\mathrm{FEV}_{1}$ and $\% \mathrm{DL}_{\mathrm{co}}$ at 12 months after surgery were sometimes larger than the ppo values for the low and moderate-risk patients. Further research is needed to elucidate the postoperative pulmonary function changes of severely affected patients.

\section{Conclusions}

Improvements in pulmonary function and symptoms varied according to the resected lobe. Pulmonary function changes may relate with the location, volume, and extent of emphysematous changes of the resected lobe, and estimated time elapsed from surgery. When selecting patients for lobectomy based on $\mathrm{FEV}_{1}$ and $\mathrm{DL}_{\mathrm{co}}$ ppo values, physicians should take into account that the actual values obtained at 12 months after lobectomy become lower than the calculated ppo values in some cases. The use of $\mathrm{DL}_{\text {со }}$ or $\mathrm{DL}_{\mathrm{co}} / \mathrm{V}_{\mathrm{A}}$ ppo values for the patients' selection related to the lung resection needs further study focused on the incidence rate of complications and mortality.

\section{Acknowledgements}

We wish to thank Mr. Hironori Hanawa for his technical support to analyze the 3D-CT scan images.

\section{Footnote}

Conflicts of Interest: The authors have no conflicts of interest 
to declare.

Ethical Statement: This study was approved by the Kitasato University Medical Ethics Organization on June 28, 2013 (approval KMEO B13-110). Written informed consent was obtained from the patients.

\section{References}

1. Brunelli A, Charloux A, Bolliger CT, et al. ERS/ESTS clinical guidelines on fitness for radical therapy in lung cancer patients (surgery and chemo-radiotherapy). Eur Respir J 2009;34:17-41.

2. Ueda K, Hayashi M, Tanaka N, et al. Long-term pulmonary function after major lung resection. Gen Thorac Cardiovasc Surg 2014;62:24-30.

3. Ueda K, Murakami J, Sano F, et al. Assessment of volume reduction effect after lung lobectomy for cancer. J Surg Res 2015;197:176-82.

4. Ladurie ML, Ranson-Bitker B. Uncertainties in the expected value for forced expiratory volume in one second after surgery. Chest 1986;90:222-8.

5. Brunelli A, Refai $M$, Salati $M$, et al. Predicted versus observed FEV1 and DLCO after major lung resection: a prospective evaluation at different postoperative periods. Ann Thorac Surg 2007;83:1134-9.

6. Win T, Groves AM, Ritchie AJ, et al. The effect of lung resection on pulmonary function and exercise capacity in lung cancer patients. Respir Care 2007;52:720-6.

7. Brunelli A, Kim AW, Berger KI, et al. Physiologic evaluation of the patient with lung cancer being considered for resectional surgery: Diagnosis and management of lung cancer, 3rd ed: American College of Chest Physicians evidence-based clinical practice guidelines. Chest 2013;143:e166S-e90S.

8. Kubota M, Kobayashi H, Quanjer PH, et al. Reference values for spirometry, including vital capacity, in Japanese adults calculated with the LMS method and compared with previous values. Respir Investig 2014;52:242-50.

9. Kanda Y. Investigation of the freely available easy-touse software 'EZR' for medical statistics. Bone Marrow Transplant 2013;48:452-8.

10. Ali MK, Mountain CF, Ewer MS, et al. Predicting loss of pulmonary function after pulmonary resection for bronchogenic carcinoma. Chest 1980;77:337-42.

11. Cukic V. Reduction of pulmonary function after surgical lung resections of different volume. Med Arch
2014;68:231-5.

12. Korst RJ, Ginsberg RJ, Ailawadi M, et al. Lobectomy improves ventilatory function in selected patients with severe COPD. Ann Thorac Surg 1998;66:898-902.

13. Kim SJ, Lee YJ, Park JS, et al. Changes in pulmonary function in lung cancer patients after video-assisted thoracic surgery. Ann Thorac Surg 2015;99:210-7.

14. Merskey H, Bogduk N, editors. Classification of Chronic Pain: Descriptions of Chronic Pain Syndromes and Definitions of Pain Terms, 2nd ed. Seattle, WA: IASP Press, 1994.

15. Bendixen M, Jorgensen OD, Kronborg C, et al. Postoperative pain and quality of life after lobectomy via video-assisted thoracoscopic surgery or anterolateral thoracotomy for early stage lung cancer: a randomised controlled trial. Lancet Oncol 2016;17:836-44.

16. Bayman EO, Parekh KR, Keech J, et al. Response to "VATS vs. thoracotomy regarding postoperative chronic pain". J Thorac Dis 2017;9:E1151-3.

17. Sengul AT, Sahin B, Celenk C, et al. Postoperative lung volume change depending on the resected lobe. Thorac Cardiovasc Surg 2013;61:131-7.

18. Agostini P, Naidu B, Cieslik H, et al. Effectiveness of incentive spirometry in patients following thoracotomy and lung resection including those at high risk for developing pulmonary complications. Thorax 2013;68:580-5.

19. Malik PRA, Fahim C, Vernon J, et al. Incentive Spirometry After Lung Resection: A Randomized Controlled Trial. Ann Thorac Surg 2018;106:340-5.

20. Chhabra SK. Forced vital capacity, slow vital capacity, or inspiratory vital capacity: which is the best measure of vital capacity? J Asthma 1998;35:361-5.

21. Brusasco V, Pellegrino R, Rodarte JR. Vital capacities in acute and chronic airway obstruction: dependence on flow and volume histories. Eur Respir J 1997;10:1316-20.

22. O'Brien C, Guest PJ, Hill SL, et al. Physiological and radiological characterisation of patients diagnosed with chronic obstructive pulmonary disease in primary care. Thorax 2000;55:635-42.

23. Wahi R, McMurtrey MJ, DeCaro LF, et al. Determinants of perioperative morbidity and mortality after pneumonectomy. Ann Thorac Surg 1989;48:33-7.

24. Markos J, Mullan BP, Hillman DR, et al. Preoperative assessment as a predictor of mortality and morbidity after lung resection. Am Rev Respir Dis 1989;139:902-10.

25. Nakahara K, Ohno K, Hashimoto J, et al. Prediction of postoperative respiratory failure in patients undergoing lung resection for lung cancer. Ann Thorac Surg 
1988;46:549-52.

26. Putnam JB, Jr., Lammermeier DE, Colon R, et al. Predicted pulmonary function and survival after pneumonectomy for primary lung carcinoma. Ann Thorac Surg 1990;49:909-14; discussion 15.

27. Zeldin RA, Normandin D, Landtwing D, et al. Postpneumonectomy pulmonary edema. J Thorac Cardiovasc Surg 1984;87:359-65.

28. Hughes JM, Pride NB. Examination of the carbon monoxide diffusing capacity $(\mathrm{DL}(\mathrm{CO}))$ in relation to its KCO and VA components. Am J Respir Crit Care Med 2012;186:132-9.

29. Sakuraba M, Miyamoto H, Oh S, et al. Video-assisted

Cite this article as: Yokoba M, Ichikawa T, Harada S, Naito M, Sato Y, Katagiri M. Postoperative pulmonary function changes according to the resected lobe: a 1-year follow-up study of lobectomized patients. J Thorac Dis 2018;10(12):6891-6902. doi: $10.21037 /$ jtd.2018.11.108 thoracoscopic lobectomy vs. conventional lobectomy via open thoracotomy in patients with clinical stage IA nonsmall cell lung carcinoma. Interact Cardiovasc Thorac Surg 2007;6:614-7.

30. Mahler DA, Wells CK. Evaluation of clinical methods for rating dyspnea. Chest 1988;93:580-6.

31. Jones PW, Harding G, Berry P, et al. Development and first validation of the COPD Assessment Test. Eur Respir J 2009;34:648-54.

32. Naunheim KS, Wood DE, Krasna MJ, et al. Predictors of operative mortality and cardiopulmonary morbidity in the National Emphysema Treatment Trial. J Thorac Cardiovasc Surg 2006;131:43-53. 